\section{Evaluation of central nervous system depressant activity of Cleome rutidosperma}

\author{
Anindya Bose, ${ }^{1}$ Anuradha Khuntia,2 \\ Jayanta Kumar Gupta, ${ }^{3}$ Sudam Si 4 \\ 1Dr. BC Roy College of Pharmacy and \\ Allied Health Sciences, Durgapur; \\ 2Institute of Pharmacy and Technology, \\ Salipur, Cuttack, Orissa; ${ }^{3}$ Department of \\ Pharmaceutical Technology, Jadavpur \\ University, Kolkata; ${ }^{4}$ School of \\ Pharmaceutical Sciences, Institute for \\ Technical Education and Research, \\ Bhubaneswar, India
}

\begin{abstract}
The central nervous system (CNS) depressant activity of the ethanol extract (200 and $400 \mathrm{mg} / \mathrm{kg}$ ) and its fractions ( $200 \mathrm{mg} / \mathrm{kg}$ each) of the aerial parts of Cleome rutidosperma was investigated in various models. The tested extract and its fractions showed significant $(\mathrm{P}<0.01)$ anxiolytic, anticonvulsant activity (in treating petit mal epilepsy) without any unwanted sedation effect. These findings justify the traditional use of this plant in CNS disorders.
\end{abstract}

\section{Introduction}

Problems of stress associated with modern life are responsible for the rise in the incidence of a variety of psychiatric disorders. Benzodiazepines are the most frequently prescribed synthetic drugs for a variety of psychopharmacological conditions, particularly anxiety, depression, epilepsy and insomnia. Besides addiction liabilities, benzodiazepines adversely affect the respiratory, digestive and immune system. Chronic treatment with benzodiazepines often proves more harmful in the long term with very serious side effects such as deterioration of cognitive function, physical dependence and tolerance. 1 In this context, there has been a resurgence of interest in medicine from natural sources and there is tremendous hope that drugs of plant origin will have significantly lesser side effects than those observed with synthetic drugs while having comparable efficacy. A variety of naturally occurring drugs such as Thymus liners, Lactuca serial, Papaver somniferum (opium) and Atropa belladonna were tested for psychopharmacological effects and were found to be effective in the treatment of psychiatric disorders. $^{2}$
Cleome rutidosperma (Capparidaceae) is a low-growing herb, up to $70 \mathrm{~cm}$ tall, found in waste grounds and grassy places with trifoliate leaves and small, violet-blue flowers, which turn pink as they age. The elongated capsules display asymmetrical, dull black seeds. The plant is native to West Africa, from Guinea to Nigeria, Zaire and Angola. It has become naturalized in various parts of tropical America as well as Southeast Asia.3,4 The analgesic, antipyretic, anti-inflammatory, locomotory, antimicrobial, diuretic, laxative antioxidant, and antiplasmodial activities of the plant have already been reported. 5 -11

Cleome rutidosperma is traditionally used in the treatment of paralysis, epilepsy, convulsions, spasm, earache, pain and skin disease. ${ }^{12}$ However, there have been no scientific reports on the activity of this plant as a central nervous system (CNS) depressant. Therefore, in the light of its use in traditional medicine, the present study was undertaken to investigate CNS activity of the ethanol extract and its fractions of Cleome rutidosperma in experimental animal models.

\section{Materials and Methods}

\section{Plant material}

Plant material (whole plants) of $C$. rutidosperma was collected from North 24-Pargana district of West Bengal, India, during August 2008 and was authenticated at the Botanical Survey of Shibpur, India. A voucher specimen (CR1) has been kept in our research laboratory for future reference. The fresh plant material was washed under running tap water to remove dirt, rinsed with distilled water, shade dried and pulverized in a mechanical grinder to obtain coarse powder.

\section{Extract preparation}

The dried plant powder was extracted with $90 \%$ ethanol using a Soxhlet apparatus. The solvent was removed under reduced pressure, which gave a greenish-black colored sticky residue (yield $11.6 \% \mathrm{w} / \mathrm{w}$ on dried material basis). In order to facilitate activity guided isolations by subdividing the phytoconstituents, the mother ethanol extract of $C$. rutidosperma was fractioned successively in solvents of increasing polarity. For this purpose, a portion of the dried ethanol extract was suspended in water and fractioned successively with petroleum ether $\left(40-60^{\circ} \mathrm{C}\right)$, diethyl ether, ethyl acetate and n-butanol. The yields of the fractions were found to be $26.64 \%, 8.95 \%, 6.39 \%$, and $16.33 \% \mathrm{w} / \mathrm{w}$, respectively, of the ethanol extract. All the fractions were dried by distillation under reduced pressure and kept in a desiccator until used.
Correspondence: Anindya Bose, Dr. BC Roy College of Pharmacy and Allied Health Sciences, Durgapur, India.

Tel. +91.343.2532678 - Fax: +91.343 .2532679$

E-mail: anindyabose_in@yahoo.com

Key words: Cleome rutidosperma, CNS, anticonvulsant, potentiation, muscle relaxant, anti-anxiety.

Received for publication: 28 September 2011. Revision received: 15 February 2012.

Accepted for publication: 15 February 2012.

This work is licensed under a Creative Commons Attribution NonCommercial 3.0 License (CC BYNC 3.0).

(C) Copyright A. Bose et al., 2012

Licensee PAGEPress, Italy

Alternative Medicine Studies 2012; 2:e8

doi:10.4081/ams.2012.e8

\section{Preliminary phytochemical tests}

Standard methods were used for preliminary phytochemical screening of the extract and its fractions to identify the phytoconstituents present.13,14 These screenings include tests for alkaloids, glycosides, steroids, terpenoids, flavonoids, tannins, saponins, lipids and sugars.

\section{Animals}

Swiss albino mice of both sexes (20-25 g) were used for the study. Animals were housed in standard environmental conditions and fed with standard rodent diet and water ad libitum. All experiments were carried out according to the guidelines of our institutional animal ethics committee.

\section{Acute toxicity study}

The acute toxicity of the ethanol extract and its fractions were determined as per OECD guidelines no. 425.15 For this method, female mice were selected for the study and 100 $\mathrm{mg} / \mathrm{kg}$, p.o. was selected as starting dose. Individual animals were dosed in sequence at $24 \mathrm{~h}$ intervals, one at a time, and then observed for a minimum of $24 \mathrm{~h}$ with special attention given during the first $4 \mathrm{~h}$. Observations included mortality and clinical signs such as changes in the skin and fur, eye mucous membranes, respiratory, circulatory, autonomic central nervous systems, somatomotor activity and behavior pattern. It was decided that if the first animal died or appeared moribund the second animal would receive a lower dose. A final dose of 2000 $\mathrm{mg} / \mathrm{kg}$, p.o. was considered the upper limit dose. When a total of 3 animals had been dosed with the limit dose and no deaths had occurred, 3 male mice were tested at the same level. As there was again no lethality, the test 
was terminated. The $\mathrm{LD}_{50}$ was calculated using the maximum likelihood method.

The CNS activity of the ethanol extract of $C$. rutidosperma was evaluated using two graded doses (200 and $400 \mathrm{mg} / \mathrm{kg}$ ) to investigate the effect of dose on response. The upper dose tested was one-fifth of the highest safe dose found in toxicity studies. However, sub-fractions are enriched with a much higher concentration of selected constituents compared to the mother extract. This requires the lesser dose selection of sub-fractions to judge the activity potentiation. Therefore, ethanol extract sub-fractions were examined only at the lower dose of the extract tested (200 $\mathrm{mg} / \mathrm{kg}$ ).

\section{Anticonvulsant activity}

\section{Pentylene tetrazole induced seizures}

Animal groups were treated either with vehicle $(10 \mathrm{~mL} / \mathrm{kg}$ of $1 \%$ solution of Tween- 80 in normal saline), diazepam ( $2.0 \mathrm{mg} / \mathrm{kg}$, i.p.), ethanol extract (200 and $400 \mathrm{mg} / \mathrm{kg}$, p.o.) or its fractions $(200 \mathrm{mg} / \mathrm{kg}$, i.p.) suspended in the vehicle 30 min prior to the administration of pentylenetetrazole (PTZ) $(80 \mathrm{mg} / \mathrm{kg}$, i.p). The animals were observed for onset and duration of convulsion up to 60 min after PTZ administration. ${ }^{16,17}$

\section{Strychnine induced seizure}

The test animals were administered either with vehicle $(10 \mathrm{~mL} / \mathrm{kg})$, clonazepam $(3 \mathrm{mg} / \mathrm{kg}$, i.p.), extract (200 and $400 \mathrm{mg} / \mathrm{kg}$, p.o.) or its fractions (200 mg/kg, p.o.). Thirty minutes later all the animals were injected with strychnine hydrochloride (2 mg/kg, i.p) and observed for onset and duration of convulsion for a period of 60 min. ${ }^{18,19}$

\section{Maximum electric shock induced seizures}

Animal groups were treated with either vehicle $(10 \mathrm{~mL} / \mathrm{kg}$ of $1 \%$ solution of Tween- 80 in normal saline), diazepam ( $2 \mathrm{mg} / \mathrm{kg}$, i.p.), ethanol extract (200 and $400 \mathrm{mg} / \mathrm{kg}$, p.o.) or its fractions $(200 \mathrm{mg} / \mathrm{kg}$, p.o.) suspended in the vehicle, 30 min prior to the application of electric shock (42 MA, 0.2 Sec) using corneal electrodes of an electro convulsiometer (Techno India). ${ }^{20,21}$ The onset and duration of the tonic hind leg extension was noted.

\section{Muscle relaxant activity}

Animals were screened through rotarod apparatus rotating at a speed of $25 \mathrm{rpm}$. Animals that did not fall within $30 \mathrm{~s}$ of 3 successive trials were selected for screening. Animal groups were treated orally with either diazepam ( $2 \mathrm{mg} / \mathrm{kg}$, i.p.), ethanol extract (200 and $400 \mathrm{mg} / \mathrm{kg}$, p.o.) or its fractions (200 $\mathrm{mg} / \mathrm{kg}$, p.o.) suspended in the vehicle (10 $\mathrm{mL} / \mathrm{kg}$ of $1 \%$ suspension of Tween- 80 in normal saline). The falling time of all the animals were noted at the beginning and after $30 \mathrm{~min}$ of drug administration. ${ }^{22,23}$

\section{Anti-anxiety activity}

Anti-anxiety activity was studied by elevated plus-maze test. The plus maze apparatus consisting of two open arms $(16 \times 5 \mathrm{~cm})$ and two closed arms $(16 \times 5 \times 12 \mathrm{~cm})$ having an open roof with the plus maze elevated $(25 \mathrm{~cm})$ from the floor. Animals were treated with either vehicle $(10 \mathrm{~mL} / \mathrm{kg}$ of $1 \%$ solution of Tween- 80 in normal saline), diazepam (1 $\mathrm{mg} / \mathrm{kg}$, i.p.), ethanol extract (200 and $400 \mathrm{mg} / \mathrm{kg}$, p.o.) or its fractions $(200 \mathrm{mg} / \mathrm{kg}$, p.o.) suspended in the vehicle, $45 \mathrm{~min}$ prior to start of session. To start a session, the mouse was placed on the center of the apparatus, facing an enclosed arm. The total time spent on open arms, the number of open arm entries, and the total entries into the enclosed arms were recorded and scored for a period of $5 \mathrm{~min}$. An entry was defined as all four paws on the arm. During the entire experiment, the animals were allowed to socialize and every precaution was taken to ensure that no external stimuli could invoke anxiety in the animals. After each trial, the apparatus was wiped clean with ethanol (10\%) solution. 24,25

\section{Potentiation of sodium pentobarbitone induced sleep \\ Animal groups were treated with either} vehicle $(10 \mathrm{~mL} / \mathrm{kg}$ of $1 \%$ suspension of Tween80 in normal saline), chlorpromazine (4 $\mathrm{mg} / \mathrm{kg}$, i.p.), ethanol extract (200 and 400 $\mathrm{mg} / \mathrm{kg}$, p.o.) or its fractions $(200 \mathrm{mg} / \mathrm{kg}$, p.o.) suspended in the vehicle, $30 \mathrm{~min}$ prior to an injection of pentobarbitone sodium $(30 \mathrm{mg} / \mathrm{kg}$, i.p.). The sleeping time was noted by recording the interval between the loss and recovery of righting reflex. ${ }^{26,27}$

\section{Statistical analysis}

Results (except muscle relaxant activity) were statistically analyzed using one-way ANOVA followed by Dunnet's t-test. In case of muscle relaxant activity as observations of the same animals prior and after experimentation were compared, paired t-test was used for statistical analysis as being the most appropriate. $\mathrm{P}<0.05$ was considered significant.

\section{Results}

The results of the preliminary phytochemical screening of the ethanol extract and its fractions are given in Table 1. In acute toxicity studies, it was found that the ethanol extract and its fractions are safe up to the highest tested dose of $400 \mathrm{mg} / \mathrm{kg}$, p.o.

The results of anticonvulsant activity evaluation are shown in Tables 2, 3 and 4. The anticonvulsant activity is inversely proportional to the duration of convulsion in seconds. In the pentelenetetrazole-induced (Table 2) and strychnine induced seizure (Table 3 ) models,

Table 1. Phytochemical screening of extracts of Cleome rutidosperma aerial parts.

\begin{tabular}{ll}
\hline Extract & Phytoconstituents present \\
Ethanol extract & Lipids, steroids, terpenoids, flavonoids, tannins, saponins, sugars \\
\hline Pet-ether fraction & Lipids, steroids, terpenoids \\
Diethyl ether fraction & Steroids, terpenoids, flavonoids \\
\hline Ethyl acetate fraction & Flavonoids, tannins, saponins \\
n-butanol fraction & Flavonoids, tannins, saponins \\
\hline
\end{tabular}

Table 2. Effect of ethanol extract and its fractions of Cleome rutidosperma on pentylenetetrazole induced seizures.

\begin{tabular}{lccc} 
Treatment & Dose & N. convulsions & Duration convulsion (s) \\
Control & - & $16.1 \pm 1.4$ & $664.8 \pm 52.2$ \\
Standard (diazepam) & $2 \mathrm{mg} / \mathrm{kg}$, i.p. & A & A \\
\hline Ethanol extract & $200 \mathrm{mg} / \mathrm{kg}$, p.o. & $10.3 \pm 0.9^{*}$ & $356.6 \pm 31.7^{* *}$ \\
& $400 \mathrm{mg} / \mathrm{kg}$, p.o. & $\mathrm{A}$ & $\mathrm{A}$ \\
Petroleum ether fraction & $200 \mathrm{mg} / \mathrm{kg}$, p.o. & $3.8 \pm 0.4^{* *}$ & $135.1 \pm 25.4^{* *}$ \\
\hline Diethyl ether fraction & $200 \mathrm{mg} / \mathrm{kg}$, p.o. & $\mathrm{A}$ & $\mathrm{A}$ \\
Ethyl acetate fraction & $200 \mathrm{mg} / \mathrm{kg}$, p.o. & $4.4^{*} 0.6^{* *}$ & $181.5 \pm 21.3^{* *}$ \\
\hline N-butanol fraction & $200 \mathrm{mg} / \mathrm{kg}$, p.o. & $4.8 \pm 0.6^{* *}$ & $533.5 \pm 40.8^{* *}$ \\
\hline
\end{tabular}

Values expressed as mean \pm S.E. $(\mathrm{n}=6) .{ }^{*} \mathrm{P}<0.05$ and ${ }^{*} * \mathrm{P}<0.01$ compared with vehicle control (ANOVA followed by Dunnet's t-test). 'A' indicates absence of convulsion. 
ethanol extract and its fractions showed significant $(\mathrm{P}<0.05)$ anticonvulsant activity compared to the tested dose of standard drug diazepam. Although, in the maximum electroshock induced seizure model (Table 4), the extract and its fractions did not exhibit any significant anticonvulsant effect.

The ethanol extract and its fractions of Cleome rutidosperma significantly reduced the time spent with the animals on the rotarod $(\mathrm{P}<0.05)$ (Table 5). However, the effect was of a much shorter duration than that of the standard drug diazepam (1 mg/kg, i.p.). Tested at elevated plus maze, the extract and its fractions significantly $(\mathrm{P}<0.05)$ increased the exploration and the time spent in the open arms (i.e. anxiolytic like action) (Table 6). The effect was comparable to that of the standard drug diazepam ( $1 \mathrm{mg} / \mathrm{kg}$, i.p.) for all the extract fractions. However, the ethanol extract and its fractions did not significantly potentiate pentobarbitone induced sleeping time (Table 7).

\section{Discussion}

Prevention of seizures induced by maximum electroshock and pentelenetetrazole in laboratory animals is the most commonly used preliminary screening tests for characterizing potential anticonvulsant drugs. In the maximal electroshock test, the seizure induction is simple and it has a high predictive value for detecting clinically effective antiepileptic activity. 28,29 The maximal electroshock test identifies the agents with activity against generalized tonic clonic seizures occurring in the grand mal epilepsy.28 The pharmacology of acute maximal electroshock does not differ from the pharmacology of generalized tonicclonic seizures in genetic models with chronic epilepsy, e.g. audiogenic seizure susceptible mice and rats or epileptic animals. ${ }^{29}$ In addition to identifying drug activity against generalized tonic-clonic seizures, it has often been proposed that the maximal electroshock test predicts anticonvulsant drug effects against partial seizures.

In contrast, the pentelenetetrazole test represents a valid model for human generalized myoclonic and also for absence seizures. ${ }^{30}$ Generally compounds with anticonvulsant activity in the petit mal epilepsy are effective in the pentelenetetrazole-induced seizure model. ${ }^{31}$ Data from the study showed that the tonic convulsion produced by pentelenetetrazole was significantly delayed by ethanol extract of Cleome rutidosperma. The data also showed that diazepam antagonizes the pentelenetetrazole-induced convulsion. According to Sarro et al, pentelenetetrazole may be exerting its convulsive effect by inhibiting the activity of gamma amino butyric acid (GABA) at
GABAA receptors, the major inhibitory neurotransmitter which is implicated in epilepsy. ${ }^{32}$ The enhancement and inhibition of the neurotransmission of GABA will respectively attenuate and enhance convulsion. ${ }^{33,34}$ Phenobarbitone and diazepam have been shown to exert their antiepileptic effects by enhancing the GABA mediated inhibition in the brain. ${ }^{35}$ It is possible that diazepam and ethanol extract of Cleome rutidosperma antagonize pentelenetetrazole convulsion in this study by enhancing GABA neurotransmission. Since the ethanol extract of Cleome rutidosperma delayed the occurrence of pentelenetetrazole induced convulsion, it is probable that it may be interfering with the GABA aminergic mechanisms to exert its anticonvulsant effect.

Strychnine (glycine receptor antagonist) induced seizure is another important chemoconvulsant model. In the strychnine induced seizure model, it is known that strychnine directly antagonizes the inhibitory spinal reflexes of glycine. ${ }^{36}$ Suppression of strychnine induced seizures by ethanol extract of Cleome rutidosperma may be due to the glycerin inhibitory mechanisms.

The present study indicated, however, that ethanol extract of Cleome rutidosperma extract did not show any significant protection against maximal electroshock induced seizures but it significantly decreased the chemoconvulsant (pentelenetetrazole and strychnine) induced

Table 3. Anti-convulsant activity of ethanol extract and its fractions of Cleome rutidosper$m a$ against strychnine induced convulsion.

\begin{tabular}{lccc} 
Theatment & Dose & N. convulsions & Duration convulsion (s) \\
Control & - & $16.83 \pm 1.35$ & $832.2 \pm 68.2$ \\
Standard (diazepam) & $2 \mathrm{mg} / \mathrm{kg}$, i.p. & $5.33 \pm 0.99^{* *}$ & $288.0 \pm 26.6^{* *}$ \\
\hline Ethanol extract & $200 \mathrm{mg} / \mathrm{kg}$, p.o. & $11.00 \pm 1.34$ & $658.6 \pm 51.9^{* *}$ \\
& $400 \mathrm{mg} / \mathrm{kg}$, p.o. & $6.83 \pm 1.08^{*}$ & $423.5 \pm 34.6^{* *}$ \\
Petroleum ether fraction & $200 \mathrm{mg} / \mathrm{kg}$, p.o. & $4.50 \pm 0.99^{* *}$ & $236.8 \pm 28.3^{* *}$ \\
\hline Diethyl ether fraction & $200 \mathrm{mg} / \mathrm{kg}$, p.o. & $4.17 \pm 0.70^{* *}$ & $214.1 \pm 30.1^{* *}$ \\
Ethyl acetate fraction & $200 \mathrm{mg} / \mathrm{kg}$, p.o. & $4.63 \pm 0.67^{* *}$ & $265.5 \pm 34.4^{* *}$ \\
\hline N-butanol fraction & $200 \mathrm{mg} / \mathrm{kg}$, p.o. & $4.93 \pm 0.75^{* *}$ & $318.7 \pm 39.7^{* *}$ \\
\hline
\end{tabular}

Values expressed as mean \pm S.E. $(\mathrm{n}=6)$. ${ }^{*}<0.05$ and ${ }^{*} \mathrm{P}<0.01$ compared with vehicle control (ANOVA followed by Dunnet's $\mathrm{t}$-test).

Table 4. Effect of ethanol extract and its fractions of Cleome rutidosperma on maximal electroshock induced seizures.

\begin{tabular}{|c|c|c|c|}
\hline Treatment & Dose & Onset convulsion (s) & Duration convulsion (s) \\
\hline Control & - & $18.5 \pm 0.7$ & $112.3 \pm 8.1$ \\
\hline Standard (diazepam) & $2 \mathrm{mg} / \mathrm{kg}$, i.p. & A & A \\
\hline Ethanol extract & $\begin{array}{l}200 \text { mg/kg, p.o. } \\
400 \text { mg/kg, p.o. }\end{array}$ & $\begin{array}{l}19.0 \pm 0.9 \\
19.2 \pm 1.1\end{array}$ & $\begin{array}{l}114.5 \pm 9.4 \\
117.9 \pm 11.5\end{array}$ \\
\hline Petroleum ether fraction & $200 \mathrm{mg} / \mathrm{kg}$, p.o. & $17.8 \pm 0.7$ & $108.5 \pm 6.2$ \\
\hline Diethyl ether fraction & $200 \mathrm{mg} / \mathrm{kg}$, p.o. & $18.8 \pm 0.8$ & $111.7 \pm 11.4$ \\
\hline Ethyl acetate fraction & $200 \mathrm{mg} / \mathrm{kg}$, p.o. & $19.0 \pm 0.8$ & $112.6 \pm 8.6$ \\
\hline N-butanol fraction & $200 \mathrm{mg} / \mathrm{kg}$, p.o. & $18.7 \pm 0.9$ & $115.4 \pm 10.2$ \\
\hline
\end{tabular}

Table 5. Muscle relaxant activity of ethanol extract and its fractions of Cleome rutidosperma.

\begin{tabular}{|c|c|c|c|}
\hline \multirow[t]{2}{*}{ Treatment } & \multirow[t]{2}{*}{ Dose } & \multicolumn{2}{|c|}{ Time of fall from rotarod apparatus (s) } \\
\hline & & Before administration & After administration \\
\hline Standard (diazepam) & $2 \mathrm{mg} / \mathrm{kg}$, i.p. & $43.17 \pm 2.10$ & $5.00 \pm 0.52 * *$ \\
\hline Ethanol extract & $\begin{array}{l}200 \mathrm{mg} / \mathrm{kg} \text {, p.o. } \\
400 \mathrm{mg} / \mathrm{kg} \text {, p.o. }\end{array}$ & $\begin{array}{l}44.67 \pm 3.09 \\
46.50 \pm 3.15\end{array}$ & $\begin{array}{c}33.00 \pm 1.06 \text { * } \\
27.83 \pm 1.01 \text { ** }\end{array}$ \\
\hline Petroleum ether fraction & $200 \mathrm{mg} / \mathrm{kg}$, p.o. & $39.67 \pm 1.86$ & $22.67 \pm 1.11 * *$ \\
\hline Diethyl ether fraction & $200 \mathrm{mg} / \mathrm{kg}$, p.o. & $41.83 \pm 2.54$ & $25.17 \pm 1.35 * *$ \\
\hline Ethyl acetate fraction & $200 \mathrm{mg} / \mathrm{kg}$, p.o. & $45.50 \pm 2.49$ & $31.67 \pm 1.84 * *$ \\
\hline N-butanol fraction & $200 \mathrm{mg} / \mathrm{kg}$, p.o. & $42.67 \pm 2.76$ & $30.00 \pm 1.34 * *$ \\
\hline
\end{tabular}

Values expressed as mean \pm S.E. $(\mathrm{n}=6) .{ }^{*} \mathrm{P}<0.05$ and ${ }^{* *} \mathrm{P}<0.01$ compared to control (ANOVA followed by paired $\mathrm{t}$-test). 
Table 6. Anti-anxiety activity of ethanol extract and its fractions of Cleome rutidosperma.

\begin{tabular}{|c|c|c|c|}
\hline Treatment & $\begin{array}{c}\text { Dose } \\
(\mathrm{mg} / \mathrm{kg})\end{array}$ & $\begin{array}{l}\text { Time (s) spent } \\
\text { in open arm }\end{array}$ & $\begin{array}{l}\text { N. entries } \\
\text { in open arm }\end{array}$ \\
\hline Control & - & $25.2 \pm 1.6$ & $3.8 \pm 0.4$ \\
\hline Standard (diazepam) & $1 \mathrm{mg} / \mathrm{kg}$, i.p. & $78.0 \pm 6.5^{* *}$ & $17.2 \pm 1.6^{* *}$ \\
\hline \multirow[t]{2}{*}{ Ethanol extract } & 200 mg/kg, p.o. & $38.1 \pm 5.6$ & $5.0 \pm 0.6$ \\
\hline & 400 mg/kg, p.o. & $61.4 \pm 4.2^{* *}$ & $8.2 \pm 0.7^{* *}$ \\
\hline Petroleum ether fraction & 200 mg/kg, p.o. & $74.9 \pm 6.2 * *$ & $12.6 \pm 1.1^{* *}$ \\
\hline Diethyl ether fraction & 200 mg/kg, p.o. & $81.6 \pm 6.6^{* *}$ & $15.5 \pm 1.8^{* *}$ \\
\hline Ethyl acetate fraction & 200 mg/kg, p.o. & $71.5 \pm 4.9 * *$ & $12.9 \pm 0.9 * *$ \\
\hline N-butanol fraction & 200 mg/kg, p.o. & $65.2 \pm 5.1^{* *}$ & $10.3 \pm 0.9 * *$ \\
\hline
\end{tabular}

Table 7. Effect of ethanol extract and its fractions of Cleome rutidosperma on pentobarbitone induced sleeping time in mice.

\begin{tabular}{lcc}
\hline Treatment & Dose & Sleeping time (min) \\
Control & - & $35.72 \pm 2.88$ \\
Standard (chlorpromazine) & $4 \mathrm{mg} / \mathrm{kg}$, i.p. & $56.17 \pm 3.10^{*}$ \\
\hline Ethanol extract & $200 \mathrm{mg} / \mathrm{kg}$, p.o. & $34.62 \pm 3.08$ \\
& $400 \mathrm{mg} / \mathrm{kg}$, p.o. & $36.50 \pm 3.15$ \\
Petroleum ether fraction & $200 \mathrm{mg} / \mathrm{kg}$, p.o. & $41.68 \pm 2.87$ \\
\hline Diethyl ether fraction & $200 \mathrm{mg} / \mathrm{kg}$, p.o. & $39.83 \pm 2.53$ \\
Ethyl acetate fraction & $200 \mathrm{mg} / \mathrm{kg}$, p.o. & $37.55 \pm 2.75$ \\
\hline N-butanol fraction & $200 \mathrm{mg} / \mathrm{kg}$, p.o. & $32.67 \pm 2.77$
\end{tabular}

Values expressed as mean \pm S.E. $(\mathrm{n}=6) .{ }^{*} \mathrm{P}<0.05$ and ${ }^{* *} \mathrm{P}<0.01$ compared with vehicle control (ANOVA followed by Dunnet's $\mathrm{t}$-test).

seizures. Its action may be similar to that of benzodiazepines, i.e. enhancement of GABA neurotransmission. So the extract may be effective in tonic clonic seizures occurring in petit mal epilepsy. However, it is ineffective against generalized tonic clonic seizures occurring in grand mal epilepsy.

The elevated plus maze test is designed to detect the effect of anxiolytic drugs.37 The apparatus has two narrow enclosed arms that are bordered by high walls and two open arms that have essentially unprotected boards. Mice normally prefer to spend much of their allotted time in the former. This preference appears to reflect an aversion towards open arms, generated by a fear of open spaces. ${ }^{38}$ Drugs that increase exploration of the open arms are considered anxiolytics and the reverse holds true for exogenous compounds. ${ }^{39}$ In this regard, the ethanol extract and its fractions of Cleome rutidosperma increased the exploration and the time spent in the open arms in the elevated plus-maze test indicating their anxiolytic action. Furthermore, the extract and its fractions have a muscle relaxant activity, as indicated in the rotarod test, similar to anxiolytic drugs. This observed anxiolytic activity is in agreement with the decrease in spontaneous locomotory activity produced by the various extracts of Cleome rutidosperma. ${ }^{6}$

Pentobarbital is metabolized in the liver by an oxidative pathway that involves cytochrome
P450, NADPH and molecular $\mathrm{O}_{2} .40$ Drugs which enhanced barbiturate induced sleep should possibly exert an inhibition of liver enzyme system, such as CYP 450 by CEAp which metabolizes intermediate and short-acting barbiturates. The ethanol extract and its fractions of Cleome rutidosperma did not potentiate the pentobarbitone induced sleeping time indicating their inability to inhibit the hepatic microsomal enzymes responsible for metabolizing potentiation.

In summary, it can be concluded that the overall CNS depressant activity of ethanol extract of $C$. rutidosperma in various models was observed to be dose dependent, comparable with the tested dose of the standard drug diazepam, and potentiated by fractionation. The order of activity of extract fractions was: petroleum ether fraction $>$ diethyl ether fraction $>$ n-butanol fraction $>$ ethyl acetate fraction.

Therefore, the non-polar fractions (petroleum ether and diethyl fractions) of the ethanol extract containing phytoconstituents, such as steroids, terpenoids, etc., are the most promising for promoting CNS depressant activity.

This finding may encourage use of Cleome rutidosperma as an anxiolytic, anticonvulsant agent (in treating petit mal epilepsy) which could be devoid of any unwanted effect such as sedation. The plants containing steroids, triterpenoids, saponins or flavonoids exhibit anticonvulsant activity. ${ }^{41-46}$ Therefore, the presence of the above constituents as found in the ethanol extract of $C$. rutidosperma and its fractions may be responsible for its CNS activity. So, it is worthwhile isolating the bioactive principles responsible for these activities mainly from the non-polar fractions of the ethanol extract of the $C$. rutidosperma. These findings also justify the traditional use of this plant in CNS disorders.

\section{References}

1. Dhawan K, Dhavan S, Chhabra S. Attenuation of benzodiazepine dependence in mice by a trisubstituted benzoflavone moiety of Passiflora incarnata Linneous: A non habit forming anxiolytic. J Pharm Pharm Sci 2003;6:215-22.

2. Abid M, Hrishikeshavan HJ, Asad M. Pharmacological Evaluation of Pachyrrhizus erosus (L) seeds for central nervous system depressant activity. Indian $\mathrm{J}$ Physiol Pharm 2006;50:143-51.

3. Widespread JM. Flora Malesiana Series-I 1972;6:61.

4. Waterhouse B, Mitchell A. Northern Australia Quarantine Strategy Weeds Target List. AQIS Miscellaneous Publication, Canberra, Australia, 1988.

5. Bidla G, Titanji VPK, Joko B, et al. Antiplasmodial activity of seven plants used in African folk medicine. Indian $\mathrm{J}$ Pharm 2004;36:245-6.

6. Bose A, Saravanan VS, Karunanidhi N, et al. Analgesic and Locomotor Activity of Extracts of Cleome rutidosperma DC. Indian J Pharm Sci 2004;66:795-7.

7. Bose A, Gupta JK, Ghosh T, et al. Antimicrobial activity of certain extracts of Cleome rutidosperma. Indian J Nat Prod 2005;21:39-41.

8. Bose A, Mondal S, Gupta JK, et al. Studies on diuretic and laxative activity of ethanol extract and its fractions of Cleome rutidosperma aerial parts. Pharmacognosy Magazine 2006;7:178-82.

9. Bose A, Mondal S, Gupta JK, et al. Analgesic, anti-inflammatory and antipyretic activities of the ethanol extract and its fractions of Cleome rutidosperma. Fitoterapia 2007;78:515.

10. Bose A, Mondal S, Gupta JK, et al. Antioxidant and free radical scavenging activities of Cleome rutidosperma. Oriental Pharm Exp Med 2008;8:135-45.

11. Bose A, Smith PJ, Lategan CA, et al. Studies on in vitro antiplasmodial activity of Cleome rutidosperma. Acta polanica Pharmaceutica-Drug Research 2010;67: 315-8.

12. Burkill HM. The useful plants of west trop- 
ical Africa, vol. 1 (Families A-D), 2nd ed., Royal Botanic Gardens, United Kingdom, 1985.

13. Trease GE, Evans WC. Pharmacognosy, 13th ed., ELBS Publication, Delhi, India, 1989.

14. Harborne JB. Phytochemical methods a guide to modern techniques of plant analysis, 2nd ed., Chapman and Hall, New York, USA, 1984.

15. OECD. OCDE Guideline for the Testing of Chemicals. Revised Draft Guideline 425: Acute Oral Toxicity, USA, 1998.

16. Gupta M, Mazumder UK, Chakraborty S. CNS activities of methanol extract of Moringa oleifera root in mice. Fitoterapia 1999;70:244-50.

17. Pal D, Sahoo M, Mishra AK. Analgesic and anticonvulsant effects of saponin isolated from the stems of Opuntia vulgaris mill. in mice. European Bulletin of Drug Research 2005;13:91-7.

18. Ngo Bum E, Schmutz M, Meyer C, et al. Anticonvulsant properties of the methanol extract of Cyperus articulatus (Cyperaceae). J Ethnopharmacol 2001;76:145-50.

19. Said MM, Ahmed AAE, El-Alfy AT, et al. Synthesis and Pharmacological Screening for Muscle Relaxant, Anticonvulsant, and Sedative Activities of Certain Organic Compounds Produced by Michael Addition. Arch Pharm Res 2004;27:1194-201.

20. Swinyard EA, Brown WC, Goodman LS. Comparative assay of antiepileptic drugs in mice and rats. J Pharmacol Exp Ther 1952;106:319-30.

21. Bigonia P, Rana AC. Psychopharmacological profile of hydro-alcoholic extract of Euphorbia neriifolia leaves in mice and rats. Indian J Exp Biol 2005;43:859-62.

22. Dunham NW, Miya TS. A note on simple apparatus for detecting neurological deficit in rats and mice. Journal of the American Pharmacists Association 1957;46:208-9.

23. Allmark MG, Bachinski WM. A method of assay for curare using rats. Journal of the American Pharmacists Association 1949;
38:43-5.

24. Lister R.G. The use of a plus-maze to measure anxiety in the mouse. J Psychopharmacol 1987;92:180-5.

25. Rabbani M, Sajjadi SE, Jafarian A, et al. Anxiolytic effects of Salvia reuterana Boiss. on the elevated plus-maze model of anxiety in mice. J Ethnopharmacol 2005; 101:100-3.

26. Dandia PC, Collumbine H. Studies on Acorus calamus (III): some pharmacological properties of the volatile oil. J Pharmacol Exp Ther 1959;125:353-9.

27. Singh S, Rehan HMS, Majumdar DK. Effect of Ocimum sanctum fixed oil on blood pressure, blood clotting time and pentobarbitone induced sleeping time. J Ethnopharmacol 2001;78:139-43.

28. White HS. Clinical significance of animal seizure models and mechanism of action, studies of potential antiepileptic drugs. Epilepsia 1995;38:509-17.

29. Loscher W. Animal models of epilepsy for the development of antileptogenic and disease modifying drugs: A comparison of pharmacology of kindling and poststatus epilepticus models of temporal lobe epilepsy. Epilepsy Res 1999;50:105-23.

30. Rasilingam D, Srinivasan DS, Subramanian R. Anticonvulsant activity of bioflavonoid gossypin. Bangladesh J Pharmacol 2009;4:51-4.

31. Loscher W, Schmidt D. Which animal models should be used in the search for new antiepileptic drugs? A proposal based on experimental and clinical considerations. Epilepsy Res 1988;2:145-81.

32. De Sarro A, Cecchetti V, Fravolini V, et al. Effects of novel $\beta$-desfluroquinolones and classic quinolones on pentelenetetrazoleinduced seizures in mice. Antimicrob Agents Ch 1999;43:1729-36.

33. Meldrum BS. GABA agonists as antiepileptic agents. Adv Biochem Psychoph 1981;26:207-17.

34. Gale K. GABA and epilepsy basic concepts from preclinical research. Epilepsia 1992;33:S3-12.
35. Porter RJ, Meldrum BS. Antiseizure drugs. McGraw-Hill, New York, USA, 2001.

36. Sayin U, Cengiz S, Altug T. Vigabatin as an anticonvulsant against penteletetrazole seizures. Pharmacol Res 1993;28:325-31.

37. Hogg S. A review of the validity and variability of the elevated plusmaze as an animal model of anxiety. Pharmacol Biochem Behav 1996;54:21-30.

38. Rodgers RJ, Dalvi A. Anxiety, defense and the elevated plus-maze. Neurosci Biobehav R 1997;21:801-10.

39. Handley SL, McBlane JW. An assessment of the elevated X-maze for studying anxiety and anxiety-modulating drugs. J Pharmacol Toxicol 1993;29:129-35.

40. Shah VP, Yacobi A, Barr WH, et al. Evaluation of orally administered highly variable drugs and drug formulation. Pharmaceut Res 1996;13:1590-4.

41. Chauhan AK, Dobhal MP, Joshi BC. A review of medicinal plants showing anticonvulsant activity. J Ethnopharmacol 1988;22:11-23.

42. Chattopadhyay D, Arunachalam G, Mandal SC, et al. CNS activity of the methanol extract of Malloatus (Geist) Muell Arg. Leaf: An ethnomedicine of Onge. J Ethnopharmacol 2003;85:99-105.

43. Kasture VS, Kasture SB, Chopde CT. Anticonvulsive activity of Butea monosperma flowers in laboratory animals. Pharmacol Biochem Be 2002;72:965-72.

44. Librowski T, Czarnecki R, Mendyk A, et al. Influence of new monoterpenes homologues of GABA on the central nervous system activity in mice. Polish $\mathrm{J}$ Pharmacol 2000;52:317-21.

45. Santos Dos JG Jr, Blanco MM, Do Monte $\mathrm{FH}$, et al. Sedative and anticonvulsant effects of hydroalcoholic extracts of Equisetum arvense. Fitoterapia 2005;76: 508-13.

46. Johnston GAR, Bear PM. Flavonoids: Some of the wisdom of sage. Brit $\mathrm{J}$ Pharmacol 2004;142:809-10. 